\title{
Role of Glabellar flap in midfacial reconstruction
}

\author{
Haroon Rashid Zargar,Mir Mohsin,Hilal Ahmed Bhat, Raheeb Ahmed Shah,Sheikh Adil Bashir, \\ Altaf Rasool, Peerzada Umar Farooq Baba, Akram Hussain Bijli, Adil Hafeez Wani,
}

\author{
Department of Plastic \& Reconstructive Surgery, SKIMS, Srinagar
}

\section{A B S T RA C T}

\begin{abstract}
Aims:Reconstruction of midface always poses a challenge to a Plastic surgeon as one has to address the convexities and concavities which are somewhat unique to this area. Various local flaps have been used for achieving these goals. This study was conducted to evaluate the indications, feasibility, and outcome ofmidfacial reconstruction using Glabellar flaps at a tertiary care center.

Materials and Methods:This is a prospective observational study conducted in the Department of Plastic and Reconstructive Surgery of a tertiary care hospital between January 2016 to December 2019. All the patients who underwent midfacial reconstruction with Glabellar flaps during this period and consented to be a part of this study were included. Patient demographics, wound etiology and area, flap size and its mode oftransfer, number of surgeries required, type of anesthesia used, comorbid conditions, complications if any, and the results of reconstruction were recorded. All the patients were followed up till May 2020.

Results: Thirteen patients were managed with Glabellar flaps. The majority of the patients ( $n=9,69.23 \%$ ) were males, with a mean age of 34 years. The most common cause of wounds was animal bite/maul $(n=5,38.46 \%)$. The glabellar flap was most commonly used as a V-Y rotation advancement flap in nine patients (69.23\%). Most of the cases $(n=9,69.23 \%)$ were operated under local anesthesia. The donor site was closed primarily in $\mathrm{V}-\mathrm{Y}$ or linear fashion in 12 cases, and skin grafted only in 1 case. The majority ( $\mathrm{n}=12,92.3 \%)$ of the patients graded reconstruction results as Good-Excellent.

Conclusions:Glabellar flap is an excellent option for reconstruction of midfacial defects with minimal donor site morbidity and can be performed safely under local anesthesia.

Clinical Significance:A glabellar flap is an excellent option formidfacial reconstruction with minimal complications. It can be performed under local anesthesia in most cases thus minimizing patient morbidity and burden on hospital resources.

Keywords: Glabellar flap,wounds, reconstruction, face.

JMS: 2020; 23(2):20-25 DOI: https://doi.org/10.33883/jms.v23i2.754
\end{abstract}

\section{INTRODUCTION}

Reconstruction of the face always poses a challenge to a plastic surgeon as restoration of both the natural external appearance and function are the primary concerns which a reconstructive surgeon has to address. For reconstructive purposes, the face has been divided by González-Ulloa Minto units. For the ease of reconstruction, theorbital and the nasal units have been further divided into subunits. ${ }^{2,3} \mathrm{Central}$ part of the face which includes cranial half of the nose and medial canthal areasposes additional

\begin{tabular}{l|l}
\multicolumn{3}{c}{ Access this article online } \\
\hline
\end{tabular}

difficulty in reconstruction as one has to address the convexities and concavities which are somewhat unique to this area. Various local flaps like the forehead flap and its modifications $s^{4,5}$, the nasolabial flap ${ }^{6}$, the central artery perforator propeller flap ${ }^{7}$ and the Glabellar flap and its

Correspondence:

Dr. Mir Mohsin, MCh

Associate Professor

Department of Plastic \& Reconstructive Surgery, SKIMS

Email:m_mohsin@rediffmail.com

How to cite this article: Zargar HR, Mohsin M, Bhat $\mathrm{H}$, Shah R, Bashir S, Rasool A, Baba PUF, Bijli A, Wani A. Role of Glabellar flap in midfacialreconstruction.JMS 2020; 23(2):20-25

Received: 2020-06-05 Accepted: 2020-06-15 


\section{Zargar HR etal; Role of Glabellar flap in midfacial reconstruction}

various modifications ${ }^{8-10}$ have been used to reconstruct this area.What makes Glabellar flap suitable for reconstruction of these defects is that it forms a near-perfectmatch as far as the texture, consistency, and color is concerned, the secondary defect can be closed primarily and the resultant scar in the donor area falls in the natural crease of glabella which is generally well camouflaged and the surgery is usually very simple and can be performed under local anesthesia. ${ }^{11}$

\section{Anatomy:}

Glabella is defined as the area between the eyebrows. Glabella lies directly above the nose and joins the supraciliary ridge. This is an elevated area with a significant amount of redundant skin. The presence of this redundant skin has been utilized to cover the nearby areas by transferring it in many ways. ${ }^{12}$ The soft tissue of the glabellar area has four layersunder the skin which include: 1) superficial fatty layer 2)fibromuscular layer 3) deep fatty layer and 4) periosteum/perichondrium ${ }^{11}$ The fibromuscular layer has three muscles:medial part of frontalis which functions as an elevator of brows, Procerus, which when contracted produces transverse wrinkles at radix of the nose and Corrugator supercilii which draws the eyebrows down and medially on contraction. The presence of this fibromuscular layer makes this area thicker and less pliable than nearby areas. ${ }^{12}$

Both the internal as well as external carotid systems supply blood to the glabellar area but it is mainly the branches of the supratrochlear artery which is a branch of the ophthalmic artery, from the internal carotid system which supply this area. Anastomosing branches from the external carotid system through the angular artery also feed this area. ${ }^{11}$

This study was conducted to evaluate the indications, feasibility, and outcome of facial reconstruction using Glabellar flaps at a tertiary care center.

\section{MATERIALS AND METHODS}

This is a prospective observational study conducted in the Department of Plastic and Reconstructive Surgery, of a tertiary care hospital between January 2016 to December 2019. The research was conducted according to the principles of the Declaration of Helsinki. Informed consent was taken from all the patients for enrolment into the study and for use of their data including pictures for research publication.

All patients who underwent reconstruction during this period with glabellar flaps and consented to be a part of this study were included. The data about patient demography, etiology of the defect, the area of defect, size of flap, mode of transfer of flap, number of surgeries required, type of anesthesia used, comorbid conditions, complications if any, and the results of the reconstruction as judged by the patients at 6 months were recorded. Results of reconstruction were graded as Very poor, Poor, Satisfactory, Good, Very Good, Excellent by the patient. All the patients were followed up till May 2020.

\section{Surgical Technique:}

Preoperative planning was done in all patients and surgery was performed under local or general anesthesia depending upon the age of the patients, need forother surgical procedures, and patient preferences. All the surgeries were performed under loop magnification. As a first step, the defect was created (after wide local excision of tumor or debridement of the post-traumatic wound) after which foil template of the defect was made. Depending upon the size and location of the defect, the transfer of the Glabellar flap (V-Y advancement, rotation advancement, or transposition) was planned and marked. In the case of V-Y advancement, both the limbs of the flap touch the circumference of the defect whereas the apex of V lies superiorly in the glabella in the midline. The depth of incision is restricted to the subcutaneous plane and the flap is not undermined as the blood supply of flap comes from the underlying subcutaneous tissue. The V-shaped flap is advanced into the defect and the resultant secondary donor site defect is closed by advancing the adjacent tissues medially. The flap is contoured to the defect and sutured in two layers. In cases of $\mathrm{V}-\mathrm{Y}$ rotation advancement flap, the apex of the flap is located in the midline superiorly in the glabella. One arm of the flap arises from the lateral edge of the defect to the apex superomedially. The length of this arm should be longer as this is the side of the flap which will cover the defect. Both the arms of the $\mathrm{V}$ extend below the brow and the angle of $\mathrm{V}$ is restricted to $60^{\circ}$. The flap is elevated in a subcutaneous plane with the pedicle on the opposite lateral sidewall of the nose. Care is taken to preserve blood supply at the pedicle. The flap is rotated into the defect and the donor site is closed in a V-Y manner. While using as a transposition flap, the donor site defect is closed primarily whilethe whole of the flap is transposed to the nearby soft tissue defect. The wound is closed in two layers using $4 / 0$ or $5 / 0$ polyglactin suture in the subdermal plane and interrupted skin closure with $5 / 0$ or $6 / 0$ polyamide suture.

Postoperatively, the skin sutures were removed between $3^{\text {rd }}$ to $5^{\text {th }}$ day. The patients were followed weekly for three weeks, then monthly for three months and three six- 
monthly thereafter till May 2020. Additional surgeries in the form of correction of dogears were usually done after three months. At 6 months follow up, patients were asked to grade the results of their reconstruction on a scale of Very poor, Poor, Satisfactory, Good, Very good and Excellent. Any complications encountered and the measures taken for their management were recorded.

\section{RESULTS}

In this prospective study spanning over a period of four years, thirteen patients with midfacial wounds were managed with glabellar flaps. The majority of the patients $(\mathrm{n}=9,69.23 \%)$ were males, age ranging from 6 years to 73 years with a mean of 34 years. The most common cause of wounds in this area of midface was animal bite/maul $(\mathrm{n}=5$, $38.46 \%$ ) which included Bear maul in three patients (23.07\%)and dog bite in the other two. Other causes included Basal cell carcinoma in three patients $(23.07 \%)$, road traffic accidents in three patients $(23.07 \%)$, low voltage electrical burn in one patient who had awoundat the root of the nose, while one patient had exposed titanium mesh following reconstruction of frontal bone defect subsequent to a gunshot injury. The location and dimensions of the defects are enumerated in Table 1. Only one patient had comorbidity in the form of diabetes and hypertension which were controlled preoperatively withmedication. Reconstruction in three patients $(23.07 \%)$ with defects in the upper nasal areas was done with a V-Y advancement flap. In one patient who had exposed titanium mesh in the infra brow area, the reconstruction was done with a transposition flap. In the rest of the nine patients $(69.23 \%)$, reconstruction was performedusing V-Y rotation advancement flaps. The donor site was closed primarily in $\mathrm{V}-\mathrm{Y}$ or linear fashion in 12 cases, and a small skin graft was required only in 1 case. Follow up ranged from 6 months- 4 years. The majority of the patients $(92.3 \%)$ had a stable reconstruction at followup reported as Good Excellent by them and no major complications were encountered in this study (Table 1). Only one patient in whom skin graft was required for reconstruction of the Glabellar flap donor site had suboptimal cosmetic outcome and reported results as Satisfactory only.

\section{DISCUSSION}

The Glabellar flap was first reported by Carl von Graefe in 1818 in his book "Rhinoplastik". ${ }^{8}$ Initially it was used as a V-Y advancement flap based on random pattern blood supply. Later many modifications were reported. Field LM

Table 1: Patient demographic data, wound characteristics, surgical procedures, complications, and results.

\begin{tabular}{|c|c|c|c|c|c|c|c|c|c|c|c|}
\hline $\begin{array}{l}\text { S. } \\
\text { No. }\end{array}$ & $\begin{array}{l}\text { Age } \\
\text { (years) }\end{array}$ & Sex & $\begin{array}{l}\text { Etiology of } \\
\text { defect }\end{array}$ & Area involved & $\begin{array}{l}\text { Defect } \\
\text { Size } \\
(\mathrm{mm})\end{array}$ & $\begin{array}{l}\text { Mode of } \\
\text { transfer }\end{array}$ & $\begin{array}{l}\text { No. of } \\
\text { Surgerie } \\
\mathrm{s}\end{array}$ & $\begin{array}{l}\text { Type } \\
\text { of } \\
\text { Anest } \\
\text { hesia }\end{array}$ & $\begin{array}{l}\text { Complication } \\
\mathrm{s}\end{array}$ & $\begin{array}{l}\text { Follow up } \\
\text { (months) }\end{array}$ & Result \\
\hline 1 & 6 & Male & Animal bite & $\begin{array}{l}\text { Upper } 1 / 3 \text { of nose } \&(\mathrm{~L} \\
\text { )lower lid }\end{array}$ & $22 \times 30$ & $\begin{array}{l}\text { Rotation } \\
\text { Adv. }\end{array}$ & Single & G.A & None & 7 & V. good \\
\hline 2 & 73 & Female & $\mathrm{BCC}$ & (L) medial canthus & $23 \times 34$ & $\begin{array}{l}\text { Rotation } \\
\text { Adv. }\end{array}$ & 2 & L.A & None & 14 & $\begin{array}{l}\text { Excellen } \\
\mathrm{t}\end{array}$ \\
\hline 3 & 28 & Male & Gunshot & $\begin{array}{l}\text { Left Brow \& infra - brow } \\
\text { area }\end{array}$ & $29 \times 23$ & $\begin{array}{l}\text { Transp- } \\
\text { osition }\end{array}$ & 2 & G.A & None & 6 & Good \\
\hline 4 & 15 & Male & Electrical burn & Upper $1 / 2$ of nose & $32 \times 38$ & $\begin{array}{l}\text { Rotation } \\
\text { Adv. }\end{array}$ & 2 & G.A & $\begin{array}{l}\text { Interbrow } \\
\text { Narrowing, } \\
\text { Donor site } \\
\text { skin graft } \\
\text { scar } \\
\end{array}$ & 12 & $\begin{array}{l}\text { Satisfact } \\
\text { ory }\end{array}$ \\
\hline 5 & 37 & Female & Animal bite & Upper $1 / 3$ of nose & $26 \times 33$ & V-Y Adv. & 2 & G.A & None & 16 & V. good \\
\hline 6 & 17 & Male & Animal bite & $\begin{array}{l}\text { Upper } 1 / 3 \text { of nose } \\
\text { (L)medial canthus }\end{array}$ & $27 \times 31$ & $\begin{array}{l}\text { Rotation } \\
\text { Adv. }\end{array}$ & 2 & L.A & None & 8 & $\begin{array}{l}\text { Excellen } \\
\mathrm{t}\end{array}$ \\
\hline 7 & 27 & Male & Animal bite & Upper $1 / 3$ of nose & $24 \times 27$ & $\begin{array}{l}\text { Rotation } \\
\text { Adv. }\end{array}$ & 1 & L.A & None & 11 & $\begin{array}{l}\text { Excellen } \\
\mathrm{t}\end{array}$ \\
\hline 8 & 62 & Female & $\mathrm{BCC}$ & (L) medial canthus & $28 \times 30$ & $\begin{array}{l}\text { Rotation } \\
\text { Adv. }\end{array}$ & 1 & L.A & None & 17 & $\begin{array}{l}\text { Excellen } \\
\mathrm{t}\end{array}$ \\
\hline 9 & 67 & Male & $\mathrm{BCC}$ & $\begin{array}{l}\text { (R) medial canthus and } \\
\text { medial } 1 / 3 \text { of }(R) \text { upper } \\
\text { eyelid }\end{array}$ & $30 \times 34$ & $\begin{array}{l}\text { Rotation } \\
\text { Adv. }\end{array}$ & 2 & L.A & None & 9 & V. good \\
\hline 10 & 33 & Female & RTA & Upper $1 / 3$ of nose & $22 \times 27$ & V-Y Adv. & 1 & L.A & None & 22 & V. good \\
\hline 11 & 14 & Male & RTA & Upper $1 / 3$ of nose & $26 \times 23$ & V-Y Adv. & 1 & L.A & None & 8 & $\begin{array}{l}\text { Excellen } \\
\mathrm{t}\end{array}$ \\
\hline 12 & 41 & Male & Animal bite & $\begin{array}{l}\text { Upper } 1 / 3 \text { of nose } \\
\text { (R)medial canthus }\end{array}$ & $32 \times 34$ & $\begin{array}{l}\text { Rotation } \\
\text { Adv. }\end{array}$ & 2 & L.A & None & 24 & $\begin{array}{l}\text { Excellen } \\
\mathrm{t}\end{array}$ \\
\hline 13 & 22 & Male & RTA & Upper $1 / 2$ of nose & $27 \times 32$ & $\begin{array}{l}\text { Rotation } \\
\text { Adv. }\end{array}$ & 1 & L.A & $\begin{array}{l}\text { InterbrowNar } \\
\text { rowing }\end{array}$ & 16 & Good \\
\hline
\end{tabular}


Zargar HR etal; Role of Glabellar flap in midfacial reconstruction
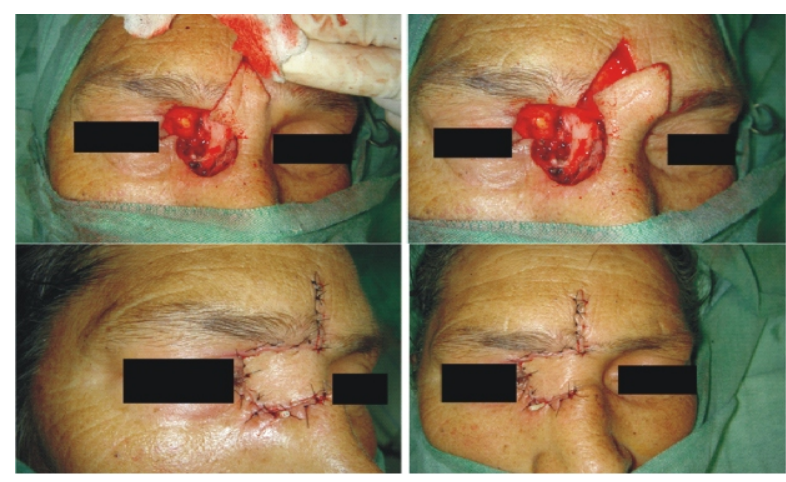

Fig. 1:Basal cell carcinoma excised and the defect involving the root of nose, medial canthal region, and part of upper eyelid reconstructed with a transposed Glabellar flap, donor site closed primarily in a linear fashion.

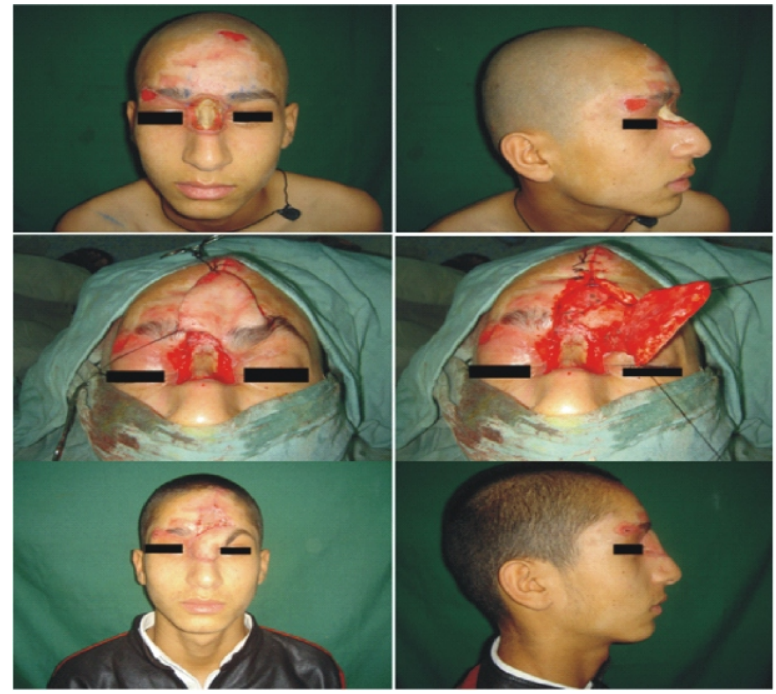

Fig. 2:Post electric burn complex wound at the root of nose with exposed nasal bones reconstructed with a big Glabellar flap and skin grafting of the flap donor site.

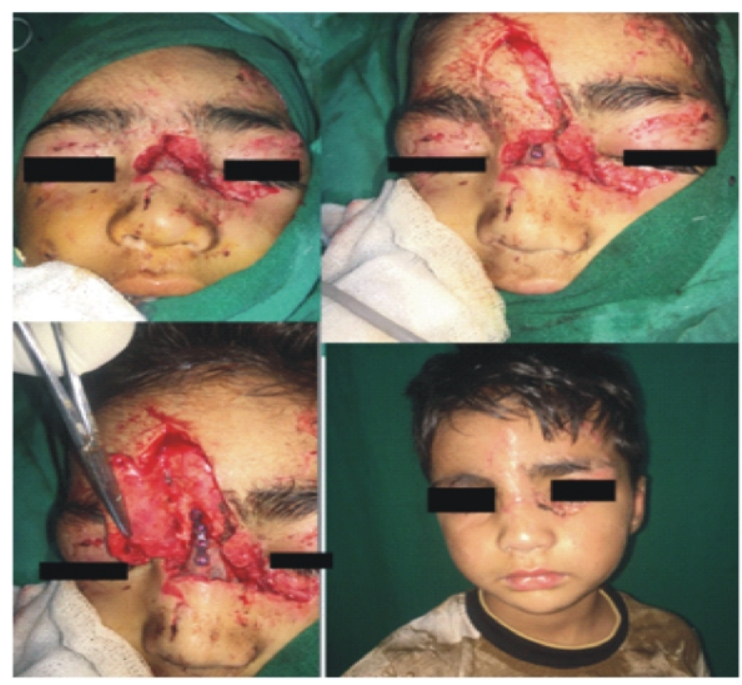

Fig. 3:Maxillofacial trauma with exposed bone and titanium plate at the frontonasal region, reconstructed with a Glabellar flap. The donor site closed primarily in a V-Y fashion. 


\section{Zargar HR etal; Role of Glabellar flap in midfacial reconstruction}

described a modification of this flap which he called Glabellar transposition banner flap, in which the pedicle of the flap arises from the lateral nasal sidewall on the side opposite the defect. ${ }^{8}$ A bipedicled modification of this flap was also described by Field LM . ${ }^{13}$ Morrison WA, et al described reverse island Glabellar flap based on terminal branches of the contralateral angular artery for the closure of defects of the nasal tip, alar lobule and columella. ${ }^{14}$ Seyhan $\mathrm{T}$ modified the reverse island glabellar flap and based it on the dorsal nasal branch of ophthalmic vessels with a better survival rate and called it "Redix nasi island flap". ${ }^{15}$ The dorsal nasal flap was introduced as a modification of Glabellar flap by Reiger RA in 1967 who used it to reconstruct defects of the lower third of the nose as an advancement flap. ${ }^{16}$ MarchacD modified Rieger's flap by narrowing the pedicle and creating axial flap based on vessels emerging from medial canthus which allowed radical sliding and rotation of dorsal nasal skin. ${ }^{17}$

The central part of the face is a common site for BCC and curative surgery usually results in a defect that may need flap cover. ${ }^{18}$ In our study, three patients had BCC; other causes of the defects which needed glabellar flaps were road traffic accidents, animal bites/mauls, and one patient with an electrical burn. Yildirim S et al reported 23 cases of BCC in the medial canthal area which were reconstructed by Glabellar flaps. ${ }^{9}$ Emsen IM and Benlier E successfully reconstructed post BCC excision medial canthal defects in eight patients with thinned glabellar flaps. ${ }^{10}$

For larger defects of this area, the glabellar flap can be used in combination with other local flaps to cover the defect. Yildirim $\mathrm{S}$ et al used combined Nasolabial V-Y advancement and Glabellar flaps for reconstruction of large medial canthal defects successfully in 23 patients. ${ }^{9}$ Spinelli $\mathrm{HM}$ et aldivided the periocular region into 5 zones and recommended selection of reconstruction for each zone considering regional features of each zone. ${ }^{19}$ For the medial canthal zone of the periorbital area, they recommended upper eyelid myocutaneous flap but for larger defects of this area,OginoA et al used a combination of Glabellar and lid myocutaneous flap for reconstruction. ${ }^{20}$ The use of glabellar flap in combination with the Rintala flap was advocated by Onishi Ket al. ${ }^{21}$

The advantage of this flap is that it is harvested from the adjoining area that provides excellent color and texture match of the reconstructed area with the surrounding skin. ${ }^{11}$ The reconstruction with this flap can be done under local anesthesia thereby avoiding the complications of general anesthesia. In a series of 23 patients for the reconstruction of medial canthal defects using combined glabellar and nasolabial flaps, Yildirim $\mathrm{S}$ et al performed all reconstructions under local anesthesia. ${ }^{9}$ In our series, most of the surgeries were performed $(n=9,69.23 \%)$ under local anesthesia.

The glabellar flap has its own share of disadvantages, one of themis the thickness of flap in comparison to the nearby recipient areas which can be addressed by thinning it in the next stage safely because of rich subdermal blood supply in this area. ${ }^{10}$ None of our patients had this issue as thinning of the flap was done whenever it was required. Narrowing of the brows is another disadvantage of this flap more so in cases in whom wide flaps are used. ${ }^{12}$ In the patients in whom less wide flaps are harvested and closure is done in V-Y fashion, this complication can be avoided. In our series of 13 patients, we encountered this problem in two patients who have advised epilation as a remedy. Pincushion deformityis usually seen in patients in whom island flaps are used and this can be the reason for the suboptimal cosmetic outcome and can be very difficult for a plastic surgeon to rectify. ${ }^{14} \mathrm{We}$ did not encounter this deformity in our study because island flap was not done in our series.

The majority of the patients $(n=12,92.3 \%)$ graded reconstruction results as Good-Excellent except for one patient who graded reconstructive results as satisfactory only as he was not so happy about the flap donor site skin graft scar as far as cosmesis is concerned. Skin grafts should preferably be avoided at donor sites by keeping the flap width just enough to be closed primarily or else the donor site should be left to heal by secondary intention which has better results than skin grafts. ${ }^{22}$

\section{CONCLUSIONS}

Glabellar flap is an excellent option for reconstruction of midfacial defects with minimal donor site morbidity and can be performed safely under local anesthesia. Skin grafts should preferably be avoided for flap donor site reconstruction.

Clinical Significance: A glabellar flap is an excellent option for midfacial reconstruction with minimal complications. It can be performed under local anesthesia in most cases thus minimizing patient morbidity and burden on hospital resources.

Acknowledgments: We would like to acknowledge the whole staff of our department who helped in one way or another in conducting this study. The authors declare that there is no conflict of interest and there are no financial 
Zargar HR etal; Role of Glabellar flap in midfacial reconstruction

disclosures to be made.

Conflict of interest: Nil

Financial Support: Nil

Written Informed consent: Taken

\section{REFERENCES}

1. González-Ulloa M. Regional aesthetic units of the face. Plast Reconstr Surg. 1987 Mar;79(3):48990.

2. Özkaya Mutlu Ö, Egemen O, Dilber A, Üsçetin I. Aesthetic Unit-Based Reconstruction of Periorbital Defects. J Craniofac Surg. 2016 Mar;27(2):42932.

3. Cerci FB. Usefulness of the subunit principle in nasal reconstruction. An Bras Dermatol. 2017;92(5 Suppl 1):15962.

4. Stigall LE, Bramlette TB, Zitelli JA, Brodland DG. The Paramidline Forehead Flap: A Clinical and Microanatomic Study. Dermatol Surg. 2016 Jun;42(6):76471.

5. Chiummariello S, Del Torto G, Iera M, Alfano C. The use of local flaps in the one-step nose reconstruction after cancer resection. Ann Ital Chir. 2013 Jul 2;84(ePub).

6. Kerem H, Bali U, Sönmez E, Manavbaşı YI, Yoleri L. The cranially based contralateral nasolabial flap for reconstruction of paranasal and periorbital surgical defects. J Plast Reconstr Aesthet Surg. 2014 May;67(5):65561.

7. Baltu Y, Dölen UC, Aydin O. Extended Central Artery Perforator Propeller Flap for Large Nasal Defects. J Craniofac Surg. 2019 Dec;30(8):240811.

8. Field LM. The glabellar transposition "banner" flap. J Dermatol Surg Oncol. 1988 Apr;14(4):3769.

9. Yildirim S, Aköz T, Akan M, Cakir B. The use of combined nasolabial V-Y advancement and glabellar flaps for large medial canthal defects. Dermatol Surg. $2001 \mathrm{Feb} ; 27(2): 2158$.

10. Emsen IM, Benlier E. The use of the superthinned inferior pedicled glabellar flap in reconstruction of small to large medial canthal defect. J Craniofac Surg. 2008 Mar;19(2):5004.
11. Sanjuan-Sanjuan A, Ogledzki M, Ramirez CA. Glabellar Flaps for Reconstruction of Skin Defects. Atlas Oral Maxillofac Surg Clin North Am. 2020 Mar;28(1):438.

12. Koch CA, Archibald DJ, Friedman O. Glabellar flaps in nasal reconstruction. Facial Plast Surg Clin North Am. $2011 \mathrm{Feb} ; 19(1): 11322$.

13. Field LM. The use of a bipedicled flap for defects on the bridge of the nose. J Dermatol Surg Oncol. 1980 Mar;6(3):2002.

14. Morrison WA, Donato RR, Breidahl AF, Theile DR, Callan PP. Island inner canthal and glabellar flaps for nasal tip reconstruction. Br J Plast Surg. 1995 Jul;48(5):26370.

15. Seyhan T. The radix nasi island flap: a versatile musculocutaneous flap for defects of the eyelids, nose, and malar region. J Craniofac Surg. 2009 Mar;20(2):51621.

16. Rieger RA. A local flap for repair of the nasal tip. Plast Reconstr Surg. 1967 Aug;40(2):1479.

17. Marchac D. [The naso-frontal rotation flap]. Ann Chir Plast. 1970;15(1):449.

18. Choi JH, Kim YJ, Kim H, Nam SH, Choi YW. Distribution of Basal Cell Carcinoma and Squamous Cell Carcinoma by Facial Esthetic Unit. Arch Plast Surg. 2013 Jul;40(4):38791.

19. Spinelli HM, Jelks GW. Periocular Reconstruction: A Systematic Approach. Plast Reconstr Surg. 1993 May;91(6):10171024.

20. Ogino A, Onishi K, Okada E, Nakamichi M. Medial canthal reconstruction with multiple local flaps. JPRAS Open. 2017; 15:4-9.

21. Onishi K, Maruyama Y, Okada E, Ogino A. Medial Canthal Reconstruction with Glabellar Combined Rintala Flaps.Plast Reconstr Surg. 2007 Feb;119(2):537541.

22. Correa BJ, Weathers WM, Wolfswinkel EM, Thornton JF. The forehead flap: the gold standard of nasal soft tissue reconstruction. Semin Plast Surg. 2013;27(2):96-103. 